\title{
Deserción de cierto desierto
}

LA DISYUNTIVA CIVILIZACIÓN O BARBARIE, que Sarmiento plantea en Facundo, implica básicamente el enfrentamiento de dos modelos de país, el existente al momento del ensayo (1845) o un estado moderno, concebido según las ideas liberales, por entonces de moda en Europa.

Consumada la Revolución de Mayo, Argentina inicia su vida como nación independiente con la herencia del inmenso baldío español -denunciado por Alberdi-: casi 3 millones de $\mathrm{Km}^{2}$ con menos de 500 mil habitantes, en su mayoría dispersos y viviendo de los frutos que espontáneamente brinda el suelo. El pan que a veces se amasa es de harina importada.

Este estado de cosas tendría origen en la desobediencia a las Leyes de Indias, que permitió la división de la tierra al modo feudal, dejando enormes extensiones en pocas manos al amparo de la autoridad; en disposiciones que impedían radicar en el extranjero; y en el desprestigio de la agricultura, "oficio de esclavos".

Tanto las medidas previas como los primeros intentos de colonización con inmigrantes han de llevar la impronta rivadaviana. Varias fueron las dificultades con que tropezaron, pero fracasaron básicamente por la debilidad política en que vivía el país.

Con Rosas en el poder no se producen asentamientos de colonias. Pero, inmediatamente después de Caseros, la radicación de agricul tores europeos cobra renovada actualidad entre los hombres que gobiernan. "El fin capital de la constitución es poblar. La población es el fin y el medio al mismo tiempo", sostendrá Alberdi en las Bases y esta convicción prodominará en los constituyentes del 53. Con tal premisa se implementaran los medios para atraer contingentes de ultramar a los efectos de ser asimilados a una nueva estructura productiva, que permita àl país "entrar en el concierto de naciones civilizadas del orbe", es decir, en la división internacional del trabajo. 
Esta política progresista será coincidente con la tendencia expansionista de los países de Europa en los que la revolución industrial ha modificado la demanda y las estructuras productivas. Los más desarrollados necesitan impulsar economías primarias fuera de sus territorios con el fin de obtener alimentos y materias primas, expandir mercados, disminuir tensiones sociales. Inglaterra, Francia y Alemania serán las primeras naciones que estimularán la emigración hacia zonas coloniales.

En 1856 nacerá la primera colonia en nuestro país que, luego de duros inicios, con auxilio de los gobiernos de Santa Fe y de la Confederación, logrará mantenerse y crecer, para transformarse en la actual ciudad de Esperanza. Nuestra provincia que había conocido una temprana experiencia de colonización (Calera de Baruín, 1825), frustrada principalmente por el aislamiento al que quedó expuesta en un medio dominado por terratenientes hostiles al cultivo de la tierra, tuvo su primera colonia próspera en 1857, San José, que dará origen a la actual ciudad de Colón. El año siguiente será fundada Villa Urquiza sobre restos de la antigua Colonia Las Conchas, que establecida en 1853 tuvo vida efímera. En todos los casos el agricultor se convertía en propietario del lote al cabo de 5 años de trabajarlo.

Pero el criterio con que fueron establecidos aquellos primeros emplazamientos, realizados al amparo oficial, que al mismo tiempo que la productividad general resguradaban el afincamiento definitivo de los campesinos y sus intereses, no se mantendrá. "Lamentablemente la colonización en el más estricto concepto que de ella tuvieron sus propulsores más lúcidos, fue demasiado breve; no constituyó la regla sino la excepción", dirá Panettieri. La cesión de grandes extensiones gratuitamente o a bajo precio, acorde a la mentalidad ganadera de la época - que en nada contemplaba los intereses generales del país y los particulares del campesino inmigrante - permitió la colonización por parte de empresas privadas o terratenientes que loteaban sus latifundios, reservándose fracciones que resultaban valorizadas por el establecimiento de colonias vecinas. La indiferencia del estado ante la generalización de arreglos particulares condujo a la explotación y dificultó al colono su acceso a la propiedad de la tierra que trabajaba. En su mayoría fueron arrendatarios, medieros o peones.

Por su parte afirma Gori que, dirigidos los inmigrantes hacia el interior por la clase gobernante, caracterizada por su especulación en tierra pública - y después también en la privada - la verdadera colonización - aquella que entregaba gratuitamente la tierra en propiedad dividida en parcelas - fue cortada por intereses ya arraigados en el campo, y en su lugar el régimen de arrendamiento 
o de la aparcería vino a suplantarla, llamándose colonias a terrenos de propiedad privada entregados al trabajo de campesinos en situación de dependencia, arrendatarios o aparceros. Por lo que la colonización pasó a ser una denominación mal aplicada a los planes privados de subdivisión de latifundios para arrendar chacras dentro de ellos. Las colonias muchas veces no fueron más que tierras en manos de una persona o sociedad comercial, trabajadas por campesinos cuya estabilidad sobre ellas dependía de los exclusivos intereses del propietario.

Con los resultados de las primeras colonias a la vista se deseaba una verdadera "fiebre californiana" en la que fuertes capitales se lanzan a la aventura de comprar grandes extensiones, presentando ambiciosos proyectos de colonización, con los que en muchos casos además de privar al trabajador del acceso a la tierra, se defraudará al estado en sus propósitos. Los excesos cometidos mediante este tipo de prácticas conducirán a que Sarmiento manifieste ante las Cámaras en 1869: "Desgraciadamente por el más imprevisor sistema de colonización que haya ensayado pueblo alguno, la parte más poblada de la república ya está poseída, sin que el inmigrante encuentre un palmo de superficie exento de las trabas que a su adquisición la propiedad particular opone".

En la postura oficial se suceden dos momentos claramente definidos respecto de la política de colonización; el inicial, donde el objetivo primordial consiste en radicar colonos y a tal fin se les facilita el acceso a la propiedad de la tierra, y otro en el que -más dependiente nuestra economía de los intereses británicos-el propósito será la producción masiva de productos agropecuarios, para lo que se requerirá mano de obra abundante y barata. En éste no preocupó constituir colonos propietarios y se delega la colonización por cuenta de la iniciativa privada. Este sistema, que fue el más difundido en nuestra provincia, y en las demás donde se practicó colonización, fue conveniente para el estado en lo inmediato, dado que los incrementos de población y producción redundaron en un rápido aumento de la riqueza, pero resultó contraproducente para los objetivos finales de la colonización, debido a un éxodo rural masivo, qué se dirigirá a buscar medios de vida más ventajosos en los centros urbanos.

En los 70 se introduce en Argentina una muy importante inversión de capitales británicos, destinada a ampliar y mejorar obras de infraestructura fundamentales para un país cuya economía gira sobre el eje de las agro-exportaciones, como son puertos, elevadores de granos y, sobre todo, ferrocarriles. El tendido de vías no respondió a un interés prioritario de integración de los distintos sectores de la nación ni al establecimiento de focos de desarrollo 
en el interior de su territorio, sino fundamentalmente al más efectivo transporte de los productos agropecuarios hacia los puertos - principalmente al de Buenos Aires - con vistas a su exportación en bruto, vale decir, prescindiendo de procedimientos de. industrialización, indispensables tanto para un mayor enriquecimiento del país, como para el desarrollo del sector industrial y, consecuentemente, para la autodeterminación económica.

El problema básico a resolver para construir una nación como la que soñaron aquellos "protopositivistas" de Sarmiento y Alberdi consistía en acabar con el desierto, poblándolo. Empresa prácticamente irrealizable cuando se tropiece con grandes territorios de propiedad privada, ensanchados por los manejos de administraciones improcedentes. Destaca Gori que Entre Ríos tuvo un antecedente asombroso con respecto al dominio de la tierra por unos pocos. En 1767, tres grandes propietarios son casi dueños de la provincia: La Compañía de Jesús, Antonio Vera y Mújica y Francisco de Larramedi. En cuanto a la entrega de tierras fiscales, por una ley de 1835 se dispone que a quienes construyan ranchos, corrales $\mathrm{e}$ introduzcan hacienda, las 600 leguas cuadradas que comprende la selva de Montiel serán entregadas en estancias de 9 leguás cuadradas, sin otro gasto que el del papel sellado.

En el ámbito entrerriano la sanción de la Constitución provincial de 1860, una abundante legislación específica y oportunas medidas ad hoc evidencían una sostenida disposición colonizadora a través de sucesivas gestiones gubernametales. Corroborando et aserto vemos que en la década del 70 , no obstante las adversas circunstancias del levantamiento de López Jordán, se producirán " 22 asentamientos coloniales.

Durante la etapa de modernización transitada por el país en los 80, Entre Ríos bajo el gobierno de Racedo procedió a la ampliación de la red ferroviaria y a la promulgación de leyes orgánicas de colonización en 1885 y 1887. Conforme a lo previsto, el tendido de vías mantuvo una relación directa con la radicación de colonias. Pero, como dirá Panettieri, "tan to para el régimen de la tierra pública como para la política migratoria se dictó una profusa legislación, que al aplicarse fue burlada en sus propósitos". Una investigación dispuesta por el Parlamento Nacional en 1889 revela flagrantes casos de "simulacros de colonización" en tierras entregadas a tales efectos' - junto con créditos para la empresa - que, al no practicarse un efectivo control nunca fueron afectadas a la. colonia. Por ineficiencia o favoritismo el estado se fue desprendiendo de grandes extensiones que irían a manos de quienes no tuvieron otra intención que el beneficio particular. La especulación siempre logró filtrarse por entre las disposiciones legales, 
impidiendo una política más conveniente y justa, que hiciera de los inmigrantes atraídos como trabajadores rurales hombres arraigados y prósperos.

Ante las evidencias del fracaso, el ministro de Gobierno, Ing. Alberto Méndez Casariego, eleva en 1904 al entonces Gobernador de Entre Ríos, Dr. Enrique Carbó, un informe donde interpreta las causas del decaimiento del proceso colonizador, que caracterizara a la provincia durante un prolongado período del siglo anterior. Alli expresa: "Dos han sido en su origen los sistemas de colonización implantados en Entre Ríos. El primero haciendo dueños de la tierra a los colonos que las cultivaban; el segundo, haciendo sólo arrendatarios y medianeros.[...] El primer sistema, despertando en el colono el amor a la tierra, estimulando el ahorro, haciendo al labrador partícipe en la valorización paulatina de la propiedad, ha. hecho colonos ricos y colonias florescientes. El segundo explotando la pobreza del colono, desterrando hábitos de perfeccionamiento en el trabajo rural, haciendo una explotación avara de la tierra... ha sido perjudicial para el colono, la agricultura y para la Provincia."

Efectivamente, los latifundios crecieron y el desierto siguió desierto. Un exiguo porcentaje de inmigrantes pudo convertirse en propietario de la tierra. Muchos regresaron a sus países de origen o emigraron a otros. Más del $40 \%$ de los que permanecieron en el país fueron asimilados por la Capital Federal donde, ocupados en cualquier actvidad, contribuyeron a su transformación teratológica. Gigantesca cabeza enarbolada en cuerpo enteco, Buenos Aires creció sin que el país se desarrollara, de espaldas y a expensas de él. Absorbió sus riquezas, empréstitos, inmigrantes y luego... también provincianos.

Argentina fue tierra de promisión para el inmigrante y Entre Ríos - junto a Santa Fe - vanguardia de la colonización - hasta la debacle del 90 . Hoy abundan argentinos lejos de su patria y entrerrianos fuera de su patria chica. Además de argentinos en cualquier parte del país imposibilitados para desarrollarse en lo que quisieran: suerte de extranjeros en su propio suelo.

Al problema del desierto se suma la deserción: de país de inmigrantes nos hemos convertido en tierra de emigrados. Si este país "real existente" responde a.algún maléfico modelo, en él sobran territorio y pobladores.

Parecería que hemos avanzado irresolutos entre la disyuntiva sarmientina. Vaya modo doloroso y extraño de conjugar, a un tiempo, civilización y barbarie. 